\title{
Dorsal Mesogastrium
}

National Cancer Institute

\section{Source}

National Cancer Institute. Dorsal Mesogastrium. NCI Thesaurus. Code C34142.

The portion of the embryonic mesentery orig inating from the dorsal wall of the abdominal cavity, which suspends the stomach by attachment to its greater curvature, contains the spleen and celiac artery, and gives rise to the greater omentum. 